\title{
O que conhecemos sobre o trabalho infantil?
}

Ana Lúcia Kassouf

Professora titular do Departamento de Economia, ESALQ/USP

\section{Palauras-chave}

trabalho infantil, causas, conseqüências.

Classificação JEL J22.

Key words

child labor, causes, consequences.

JEL Classification J22.

\section{Resumo}

O interesse em pesquisas e análises econômicas sobre o trabalho infantil ressurge por volta de 1995, principalmente graças à crescente ênfase na redução da pobreza e na acumulação de capital humano para se obter desenvolvimento, que faz com que o trabalho de crianças seja visto como um impedimento ao progresso econômico. As análises empíricas visando obter as causas, conseqüências e soluções para o trabalho infantil estão agora sendo facilitadas pelo aumento da disponibilidade de microdados e pelas facilidades computacionais disponíveis. A pobreza, a escolaridade dos pais, o tamanho e a estrutura da família, o sexo do chefe, idade em que os pais começaram a trabalhar e o local de residência são os determinantes mais analisados e dos mais importantes para explicar a alocação do tempo da criança para o trabalho. As principais conseqüências socioeconômicas do trabalho de crianças e de adolescentes são sobre a educação, o salário e a saúde dos indivíduos. Este estudo tem como objetivo apresentar, de forma resumida, o que se conhece na literatura econômica sobre trabalho infantil e indicar direções para futuros estudos.

\begin{abstract}
Interest in research and economic analysis related to child labor reappears in the literature around 1995, mainly due to a growing emphasis on the reduction of poverty and the accumulation of human capital to obtain economic development, which means that child labor is seen as an impediment to economic progress. Empirical analysis to find the causes, consequences and solutions for child labor are now being facilitated by the increase in the availability of high quality microdata and ease of obtaining computational data. Poverty, parents' education, family composition, gender of the head of the household, age parents started working and the household location are the most analyzed and important determinants to explain the allocation of the child's time to work. The most important social-economic consequences of child labor are related to the reduction in years of education, school performance, wages and health status. The objective of this study is to present a summary of what is known in the economic literature related to child labor and to indicate directions for future research.
\end{abstract}




\section{1_Introdução}

O tema trabalho infantil, assim como o tratamento analítico dado, não são tão recentes na literatura. Apesar de não ter se iniciado na Revolução Industrial, muitos historiadores apontam para um agravamento da utilização de mão-de-obra infantil nessa época. Já em 1861 o censo da Inglaterra mostrava que quase 37\% dos meninos e $21 \%$ das meninas de 10 a 14 anos trabalhavam. Pesquisa recente feita por Tuttle (1999) mostra que crianças e jovens com menos de 18 anos representavam mais de um terço dos trabalhadores nas indústrias têxteis da Inglaterra no início do século XIX e mais de um quarto nas minas de carvão. Apesar da excepcional intensidade do trabalho infantil na Inglaterra, outros países também apresentavam taxas altas de crianças trabalhando por volta de 1830 e 1840, como França, Bélgica e Estados Unidos.

Os primeiros relatos do trabalho infantil no Brasil ocorrem na época da escravidão, que perdurou por quase quatro séculos no País. Os filhos de escravos acompanhavam seus pais nas mais diversas atividades em que se empregava mãode-obra escrava e exerciam tarefas que exigiam esforços muito superiores às suas possibilidades físicas. O início do processo de industrialização, no final do sé- culo XIX, não foi muito diferente de outros países no tocante ao trabalho infantil. Em 1890, do total de empregados em estabelecimentos industriais de São Paulo, 15\% era formado por crianças e adolescentes. Nesse mesmo ano, o Departamento de Estatística e Arquivo do Estado de São Paulo registrava que um quarto da mão-de-obra empregada no setor têxtil da capital paulista era formada por crianças e adolescentes. Vinte anos depois, esse equivalente já era de 30\%. Já em 1919, segundo dados do Departamento Estadual do Trabalho, 37\% do total de trabalhadores do setor têxtil eram crianças e jovens e, na capital paulista, esse índice chegava a 40\% (Organização Internacional do Trabalho - OIT, 2001).

Basu (1999) destaca que a origem dos modelos matemáticos e de construções teóricas relacionados à problemática do trabalho de crianças pode ser encontrada em relatos de escritores como Karl Marx, Alfred Marshall e Arthur Pigou, entre outros. Marx, em 1867, já descrevia algumas das causas do trabalho infantil. Segundo ele, com o advento das máquinas, reduz-se a necessidade da força muscular, permitindo agora o emprego de trabalhadores fracos ou com desenvolvimento físico incompleto, mas com membros mais flexíveis. Assim, emprega-se o 
trabalho das mulheres e das crianças. Marx observa que o fato de a máquina reduzir o tempo necessário de trabalho, faz com que o empregador, detendo os meios de produção, acabe reduzindo o salário dos trabalhadores e, conseqüentemente, o meio de sobrevivência das famílias. A redução dos salários acaba, muitas vezes, forçando o trabalhador homem adulto a inserir toda a família no mercado de trabalho para compensar a perda de renda. Diz Marx que

[...] de poderoso meio de substituir trabatho e trabalhadores, a maquinaria transformou-se imediatamente em meio de aumentar o número de assalariados, colocando todos os membros da família do trabalhador, sem distinção do sexo e de idade, sob o dominio direto do capital... (1968, 1ivro I, v. 2, p. 449).

Marshall (1920), escrevendo em 1980 sobre o crescimento da livre indústria e da empresa, descreve que jornadas longas de trabalho de crianças já ocorriam no século XVII, isto é, antes da Revolução Industrial. Entretanto, foi no início do século XIX, principalmente nas indústrias têxteis, "onde a miséria e a enfermidade física e moral causada pelo trabalho excessivo em más condições atinge o apogeu". Marshall também mostra a importância de se investir em capital huma- no e o papel dos pais e da escola para formar jovens para um futuro melhor. Segundo ele,

There is no extravagance more prejudicial to the growth of national wealth than that wasteful negligence which allows genius that happens to be born of lowly parentage to expend itself in lowly work. No change would conduce so much to a rapid increase of material wealth as an improvement in our schools, and especially those of the middle grades, provided it be combined with an extensive system of scholarships, which will enable the clever son of a working man to rise gradually from school to school till he has the best theoretical and practical education which the age can give (Marshall, 1920, livro 4, cap. 6).

Pigou (1932) defendia a erradicação do trabalho infantil, mas estava ciente de que impedir as crianças de trabalhar poderia levar algumas famílias pobres a níveis inferiores ao de subsistência. Ciente disso, ele associava a eliminação do trabalho infantil com políticas públicas de assistência às famílias necessitadas. Segundo ele,

There is no defense for the policy of giving poor widows and incapable fathers permission to keep their children out of school and take their 
earnings. Rather, the Committee on the Employment of Children Act are wholly right when they declare: We feel, moreover, that the cases of widows and others, who are now too often economically dependent on child labor, should be met, no longer by the sacrifice of the future to the present, but, rather, by more scientific, and possibly by more generous, methods of public assistance (Pigou, 1932, parte 4, cap. 13).

Após o trabalho infantil ser largamente discutido entre escritores e pensadores do século XIX, o tema passa a ser negligenciado por economistas durante muito tempo. ${ }^{1} \mathrm{O}$ interesse em pesquisas e análises econômicas sobre o assunto só ressurge por volta de 1995. Dado que vem ocorrendo um declínio da incidência global de trabalho infantil por várias décadas, questiona-se então qual seria o fator responsável pelo aumento de interesse recente em pesquisas sobre o assunto. Basu e Tzannatos (2003a) destacam como principal fator a crescente ênfase na redução da pobreza e na acumulação de capital humano para obter desenvolvimento, que faz com que o trabalho infantil seja visto como um impedimento ao progresso econômico.

O recente interesse acadêmico coincide com a elevação do número de po- líticas nacionais e internacionais voltadas para a redução do trabalho infantil. As principais convenções internacionais englobam: a das Nações Unidas para o Direito das Crianças, em 1989, a Convenção 182 da OIT para eliminação das piores formas de trabalho infantil, em 1999, e a Declaração do Milênio com ênfase na redução da pobreza e na educação universal, estabelecida em 2000.

No Brasil, a partir de dezembro de 1998, com a aprovação da Emenda Constitucional número 20, a idade mínima de 14 anos, que havia sido estabelecida na Constituição de 1988, passa para 16 anos, salvo na condição de aprendiz entre $14 \mathrm{e}$ 16 anos de idade. Ainda a respeito da legislação brasileira, estabeleceu-se a idade mínima de 18 anos para aqueles envolvidos em trabalhos que possam causar danos à saúde e, especificamente, proíbe qualquer produção ou trabalho de manipulação de material pornográfico, divertimento (clubes noturnos, bares, cassinos, circo, apostas) e comércio nas ruas. Ademais, proíbe trabalhos em minas, estivagem, ou qualquer trabalho subterrâneo para aqueles abaixo de 21 anos.

As análises empíricas visando obter as causas, conseqüências e soluções para o trabalho infantil estão agora sendo facilitadas pelo aumento da disponibilidade de microdados e pelas facilidades com-

\footnotetext{
O declinio do trabaho

1 O declínio do trabalho infantil, que ocorreu no final do século XIX nos países europeus e nos Estados Unidos, é atribuído ao desenvolvimento econômico, ao aumento da riqueza, assim como à criação de leis, tanto regulamentando e/ou impedindo o trabalho infantil, como tornando a educação básica compulsória, o que acabou dificultando às crianças conciliarem trabalho e estudo.
} 
putacionais disponíveis, tanto de hardware como de software, que permitem analisar e testar proposições e políticas alternativas de intervenção. Isso resulta em maior entendimento dos mecanismos de alocação de tempo dentro do domicílio, suas interações com as forças de mercado e o efeito dessas interações no trabalho infantil.

No Brasil, a principal pesquisa utilizada para analisar o trabalho infantil é a Pesquisa Nacional por Amostra de Domicílios (PNAD). Outras trazem também informações importantes sobre o trabalho das crianças, como a Pesquisa Mensal de Emprego (PME), dados do Sistema Nacional de Avaliação da Educação Básica (SAEB), censo demográfico e outras.

Este estudo tem como objetivo apresentar, de forma resumida, o que se conhece na literatura econômica sobre trabalho infantil e indicar direções para futuros estudos. Inicialmente, apresentam-se idéias e dados sobre o trabalho de crianças na época da Revolução Industrial e como o tema ressurge nos anos 90 . Em seguida, são apresentados alguns modelos teóricos e econométricos utilizados mais recentemente para modelar o trabalho infantil, assim como os fatores que levam a criança a trabalhar e as conseqüências do trabalho precoce. Para fina- lizar, são apresentadas e discutidas algumas políticas públicas de combate ao trabalho infantil.

\section{2_Dados e definições do trabalho infantil}

Apesar de a incidência de trabalho infantil estar diminuindo, um grande número de crianças continua trabalhando e por um período longo de horas. O Departamento de Estatística da Organização Internacional do Trabalho estimou em 2000 que, mundialmente, existiam em torno de 211 milhões de crianças entre cinco e 14 anos trabalhando. As maiores porcentagens eram observadas na Ásia, na África e na América Latina. Enquanto a Ásia tinha a maioria dos trabalhadores infantis em termos absolutos, a África ocupava o primeiro lugar em termos relativos (Ilo, 2002).

No Brasil, dados da PNAD de 2005 mostram que ainda existem quase três milhões de crianças e jovens de cinco a 15 anos trabalhando ou 7,8\% do total nessa faixa etária, apesar de ter havido um declínio acentuado, principalmente, a partir da metade da década de 90 . Em 1992, por exemplo, havia quase cinco milhões e meio de crianças trabalhando, correspondendo a $14,6 \%$ da população entre cinco e 15 anos. Sabe-se que a 
proporção de meninos trabalhando é maior do que a de meninas, exceto no emprego doméstico, onde a maioria dos trabalhadores é mulher. Ademais, a porcentagem de trabalho infantil nas áreas rurais é bem mais elevada do que nas áreas urbanas do Brasil.

As estatísticas sobre o trabalho infantil levantadas em diversos países devem ser analisadas com cuidado, já que os valores podem estar subestimados ou superestimados. Os levantamentos de dados realizados, geralmente, contabilizam o trabalho efetuado por crianças na semana anterior à pesquisa. Entretanto, Levison et al. (2002) apontam que, se considerado o trabalho no ano, o número de trabalhadores infantis é bem maior. Isso ocorre, segundo os autores, pelo fato de uma parte do trabalho de menores ser sazonal e intermitente.

Existe ainda o problema de não se considerar o trabalho dentro do domicílio, largamente realizado por meninas, o que pode ser a explicação para o fato de haver maior porcentagem de meninos trabalhando. Em muitos países, como na Índia, o trabalho realizado por meninas dentro do domićlio é tão árduo que até as impede de estudar (Burra, 1997).

Além de problemas de subestimação, existe também o de superestimação, que ocorre ao se considerar como traba- lhador aquele que exerce atividades por uma hora ou mais na semana. Com essa definição, são consideradas economicamente ativas muitas crianças que trabalham ainda que um número reduzido de horas por semana, o que acaba nivelando o trabalho de risco exercido por menores durante longas jornadas, como o corte da cana-de-açúcar ou sisal, com uma simples ordenha de leite ou coleta de ovos na fazenda por alguns minutos por dia. Diante disso, a OIT diferencia o trabalho de menores e denomina de "child laborer" todas as crianças com menos de 12 anos exercendo qualquer trabalho e todas as de 12 a 14 anos que trabalham em atividades que não são de risco por 14 horas ou mais na semana ou uma hora ou mais na semana quando a atividade é de risco.

Para exemplificar as sub e superestimações mencionadas, utilizaremos os dados do Brasil da Pesquisa Nacional por Amostra de Domicílios (PNAD) de 2005. Considerando trabalho remunerado ou não, 2.934.724 crianças entre 5 e 15 anos trabalham uma hora ou mais na semana anterior à pesquisa, não incluindo as crianças procurando emprego ou exercendo atividades domésticas. Se considerarmos apenas aquelas exercendo atividades por 14 horas ou mais na semana, o número cai para 1.897.877. Se contabilizarmos o número de crianças trabalhando 
por uma hora ou mais na semana em qualquer trabalho que tenha tido no ano anterior à pesquisa, o número de crianças passa de 2.934.724 para 3.495.870. Se incluirmos as que trabalharam no ano e as procurando emprego tem-se 3.625.490. Se definirmos o trabalho como aquele exercido por mais de 13 horas por semana em atividades domésticas ou não, sem dupla contagem, teríamos 4.713 .439 menores, enquanto 18.059.327 trabalham ou exercem atividades domésticas por 1 hora ou mais na semana (Tabela 1 ).

Diante do exposto, fica evidente que não existe uma única definição de trabalho infantil. A maioria dos estudos, principalmente pela disponibilidade de dados, considera o trabalho de crianças por uma hora ou mais na semana. Entretanto, em pesquisas mais específicas são utilizadas informações sobre o trabalho doméstico ou a população economicamente ativa de crianças, isto é, as trabalhando e procurando emprego.

Outro ponto importante é a própria definição de criança, que difere de um país para outro. Enquanto em algumas áreas a infância é relacionada à idade cronológica, em outras, fatores sociais e culturais também são considerados. Nos estudos sobre o trabalho infantil, geralmente, estabelece-se a faixa etária a ser analisada de acordo com a legislação vigente no local de estudo, que também difere significativamente de um país para outro.

\section{Tabela 1_ Número e porcentagem de crianças trabalhando}

\begin{tabular}{|c|c|c|}
\hline Crianças de 5 a 15 anos & Número & $\%$ \\
\hline Trabalhando 14 horas ou mais na semana & 1.897 .877 & 5,0 \\
\hline Trabalhando 1 hora ou mais na semana & 2.934 .724 & 7,8 \\
\hline $\begin{array}{l}\text { Trabalhando } 1 \text { hora ou mais na semana em qualquer trabalho } \\
\text { que tenha tido no ano anterior à pesquisa }\end{array}$ & 3.495 .870 & 9,3 \\
\hline Trabalhando no ano e procurando emprego & 3.625 .490 & 9,6 \\
\hline $\begin{array}{l}\text { Trabalhando ou exercendo atividades domésticas por } 14 \text { horas } \\
\text { ou mais na semana }\end{array}$ & 4.713 .439 & 12,5 \\
\hline $\begin{array}{l}\text { Trabalhando ou exercendo atividades domésticas por } 1 \text { hora } \\
\text { ou mais na semana }\end{array}$ & 18.059 .327 & 48,0 \\
\hline
\end{tabular}

Fonte: PNAD (2005). 
A legislação brasileira é uma das mais rígidas em relação à idade mínima de ingresso no mercado de trabalho, equiparando-se aos Estados Unidos e à França. $\mathrm{Na}$ Inglaterra, por exemplo, a idade mínima é de 13 anos, na Bélgica e na maioria dos países da América Latina é de 14 e em países como Suíça, Alemanha, Itália e Chile a idade mínima é 15 anos (Ilo, 1998).

\section{Modelos teóricos explicativos do trabalho infantil}

Como descrito anteriormente, a origem dos modelos matemáticos e de construções teóricas relacionados ao fato de a criança trabalhar pode ser encontrada em relatos de escritores como Karl Marx, Alfred Marshall, Arthur Pigou e outros. Nesta seção, objetivando mostrar o desenvolvimento de pesquisas sobre o trabalho infantil, serão apresentados alguns estudos mais recentes que utilizaram modelos teóricos.

Rosenzweig (1981) emprega a teoria econômica básica de decisão familiar para explicar a alocação de tempo entre trabalho, escolaridade e lazer de crianças na Índia. Essa teoria, proposta por Gary Becker, considera que o tempo é distribuído entre trabalho, lazer e escola. Pressupõe que a família deriva utilidade a partir do consumo de bens, de serviços e de lazer, e que lazer é preferível ao trabalho.
Os indivíduos desejam o máximo de bens que podem obter. Entretanto, defrontamse com restrições de tempo e de renda. $\mathrm{O}$ desejo de consumir sempre mais bens e as restrições de tempo e renda criam regimes de trocas, uma vez que mais tempo gasto em uma determinada tarefa significa menos tempo despendido em outra. Então, a escolha de trabalhar ocorre, apesar de lazer ser preferível a trabalho, pois lazer implica menos renda para consumir bens de mercado.

A escola é vista, nesse modelo, como um investimento, com custos presentes e benefícios futuros. A troca, nesse caso, está relacionada à quantidade de bens de consumo e benefícios a que se deve renunciar no presente, uma vez que a criança não trabalha e tem custos com educação (taxas escolares, uniforme, material, transporte, etc.), com relação ao ganho adicional obtido no futuro por ter maior nível de instrução. Assim, o trabalho infantil e o tempo na escola são determinados pela alocação do tempo dos membros do domicílio em diversas atividades e o desejo por benefícios futuros, educação e consumo corrente. Qualquer fato que altere os benefícios ou custos da educação ou as restrições enfrentadas pela família poderá afetar a quantidade de educação que a criança recebe e a quantidade de tempo gasta com trabalho. 
2 Estas atividades não

precisam estar em conflito, dependendo do tempo gasto com cada uma delas.

3 Alguns estudos consideram o número de crianças ou fecundidade como decisões endógenas - Harman (1970), Da Vanzo (1972), Rosenzweig (1981). Becker e Lewis (1973) discutem a existência de troca entre qualidade e quantidade de crianças. Entretanto, neste modelo, número de crianças é considerado exógeno, seguindo, por exemplo, Jensen e Nielsen (1997) e Grootaert e Patrinos (1998).
Trabalho infantil é uma atividade que gera benefícios imediatos na forma de renda, mas também gera custos por não estudar e/ou por reduzir o tempo de lazer. ${ }^{2}$ Assim sendo, fatores que afetam os benefícios do trabalho (salário) ou os custos (retornos à educação) também afetarão a decisão com relação ao trabalho infantil.

Mais formalmente, no modelo de Rosenzweig (1981) pressupõe-se que a família maximiza uma função utilidade (U) contínua, estritamente crescente, quase-côncava e diferenciável, a qual é função de bens comprados e consumidos $(X)$, do tempo de lazer da mãe $\left(l_{m o}\right)$ e do pai $\left(l_{f a}\right)$, do tempo de lazer da criança $\left(l_{c b}\right)$, e do nível de escolaridade da criança $\left(S_{c b}\right)$, ou seja

$$
U=U\left(X, l_{m o}, l_{f a}, l_{c b}, S_{c b}\right)
$$

Para simplificar a notação, considera-se o caso de uma família com pai, mãe e uma criança. ${ }^{3}$ Generalizações podem ser observadas em Rosenzweig (1981). Pressupõe-se que o nível de escolaridade da criança requer tempo $\left(t_{s c b}\right)$ e bens $\left(X_{s}\right)$, como material escolar, taxas escolares, transporte, etc., tal como

$$
S_{c b}=s\left(t_{s c b}, X_{s}\right)
$$

A família também se defronta com uma restrição de renda total $(F)$ dada por:

$$
\begin{aligned}
F= & V+T_{m o} W_{m o}+T_{f a} W_{f a}+T_{c b} W_{c b}= \\
& =P_{x} X+W_{m o} l_{m o}+W_{f a} l_{f a}+ \\
& +P_{s} X_{s}+W_{c b}\left(l_{c b}+t_{s c b}\right)
\end{aligned}
$$

onde $V$ é a renda não-salarial; $T_{m o}, T_{f a}$ e $T_{c b}$ são o tempo total disponível da mãe, pai e criança; $W_{m o}, W_{f a}$ e $W_{b b}$ são os salários da mãe, pai e criança, e $P_{x}$ e $P_{s}$ são os preços de $X$ e $X_{s}$.

Da restrição de renda total, é possível se verificar que o rendimento total da criança é $W_{c b}\left(T_{c b}-l_{c b}-t_{s c b}\right)$. Os custos diretos da escolaridade são $P_{s} X_{s}$ e o custo do tempo de escolaridade é $W_{c b} t_{s c b}$.

A maximização da função utilidade sujeita à restrição de renda total produz um conjunto de equações de demanda para as variáveis endógenas $l_{m o}, l_{f a}, l_{c b}$, $t_{s c h}, X, X_{s}$ em função das variáveis exógenas $W_{m o}, W_{f a}, W_{c b}, P_{x}, P_{s}$, isto é,

$D=f_{D}\left(W_{m o}, W_{f a}, W_{c h}, P_{x}, P_{s}, V\right)$

onde $D$ é $l_{m o}, l_{f a}, l_{c b}, t_{s c h}, X, X$.

Tomando como base as formas reduzidas das equações de demanda, é possível analisar o efeito de uma variável exógena sobre as endógenas. Por exemplo, uma mudança no salário da criança $W_{c b}$ e no salário da mãe $W_{m o}$ sobre o tempo de trabalho da criança $t_{w c h}=T_{c b}-l_{c b}-t_{s c b}$ e sobre o tempo de trabalho da mãe $t_{\text {w }}=T_{m o}-l_{m o}$ podem ser decompostos nos efeitos preço (utilidade constante) e renda, tais como: 


$$
\begin{aligned}
& \frac{\partial t_{w m o}}{\partial W_{m o}}=\left.\frac{\partial l_{m o}}{\partial W_{m o}}\right|_{u=\bar{u}}-t_{w m o} \frac{\partial l_{m o}}{\partial F} \\
& \frac{\partial t_{w m o}}{\partial W_{c b}}=\left.\frac{\partial l_{m o}}{\partial W_{c b}}\right|_{u=\bar{u}}-t_{w c b} \frac{\partial l_{m o}}{\partial F} \\
& \frac{\partial t_{w c b}}{\partial W_{m o}}=\left.\frac{\partial\left(l_{c b}+t_{s c b}\right)}{\partial W_{m o}}\right|_{u=\bar{u}}+t_{w m o v} \frac{\partial l_{w c b}}{\partial F} \\
& \frac{\partial t_{w c b}}{\partial W_{c b}}=\left.\frac{\partial\left(l_{c b}+t_{s c b}\right)}{\partial W_{c b}}\right|_{u=\bar{u}}+t_{w c b} \frac{\partial l_{w c b}}{\partial F}
\end{aligned}
$$

Das equações (5) a (8), é possível prever o sinal positivo para o primeiro termo do lado direito dessas. Ademais, sabese que os primeiros termos das equações (6) e (7) devem ser iguais graças à condição de simetria. A simetria mostra que qualquer mudança no salário da criança terá um efeito sobre o tempo de trabalho da mãe igual ao efeito de uma mudança no salário da mãe sobre o tempo de trabalho da criança, mantido constante o nível de utilidade. Rosenzweig (1981) afirma que

como conseqüência da interdependência (efeito salário cruzado) do comportamento da oferta de trabalho dentro do domicílio, uma mudança exógena nas condições do mercado de trabalho de mulheres adultas pode ter efeitos importantes no emprego das crianças e vice-versa, sem considerar o quanto crianças e mulheres adultas são vistas pelos empregadores como substitutas.
As equações de demanda na forma-reduzida também têm grande importância pelo fato de políticas poderem ser recomendadas baseadas nas análises das relações entre variáveis. Como um exemplo, é possível observar o efeito de uma mudança no tempo de trabalho da criança na oferta de trabalho do pai $\left(t_{w f a}\right)$, isto é,

$\frac{\partial t_{w f a}}{\partial t_{w c b}}=\frac{\left.\frac{\partial t_{w f a}}{\partial W_{c b}}\right|_{u=\bar{u}}}{\left.\frac{\partial t_{w c b}}{\partial W_{c b}}\right|_{u=\bar{u}}}$

que significa que o efeito de uma restrição imposta à oferta de trabalho da criança sobre o nível de oferta de trabalho dos pais terá o mesmo sinal dado pelo efeito do salário da criança sobre a oferta de trabalho do pai, uma vez que $\partial t_{p w b} / \partial W_{c h}$ é positivo. Se a quantidade de tempo dedicada pela criança ao trabalho for pequena, então a equação,

$\frac{\partial t_{w f a}}{\partial W_{c b}}=\left.\frac{\partial l_{f a}}{\partial W_{c b}}\right|_{u=\bar{u}}-t_{w c b} \frac{\partial l_{f a}}{\partial F}$

será uma boa aproximação do efeito salário (preço) com utilidade constante.

O tempo de trabalho da criança pode ser realocado para lazer, escola, atividades domiciliares ou trabalho. A alocação do tempo das crianças pela família é feita com base na capacidade de produção da criança e dos pais no domicílio e 
no mercado de trabalho e no grau de substituição da força de trabalho entre as crianças e os seus pais. Enquanto as atividades domiciliares realizadas pelas crianças podem permitir que mães ou irmãos mais velhos entrem no mercado de trabalho, as atividades de mercado realizadas pelas crianças permitem a elas contribuírem para o aumento da renda familiar.

Os modelos de decisão familiar tentam explicar simultaneamente as decisões de consumo e trabalho infantil e, às vezes também, freqüência à escola e fecundidade. As especificações são mantidas bastante simples para permitir generalização e testes empíricos. Esses modelos são caracterizados por uma decisão única no domicílio, que só ocorre se existe um ditador ou se todos os membros têm a mesma função utilidade. Entretanto, há evidências de que esses modelos estão cada vez mais distantes da realidade, a qual mostra que, dentro do domicílio, não há um ditador, mas o que ocorre é uma barganha entre as pessoas, e o poder de barganha está relacionado com os recursos (salários) de cada indivíduo da família. Modelos envolvendo barganhas (modelos coletivos) foram então utilizados para explicar o trabalho infantil e o bemestar das crianças. Se a barganha ocorre dentro da família, isto é, entre os pais e a criança, a função utilidade da família é re- presentada por uma média ponderada das utilidades, em que os pesos dependem da renda dos pais e das crianças.

Basu (1999) apresenta uma versão simplificada do modelo coletivo envolvendo trabalho infantil, em que a família é composta por um adulto (pai ou mãe) e uma criança, sendo esses os agentes 1 e 2 , respectivamente. Pressupõe-se que existe somente um bem na economia, e $x_{i}$ é a quantidade consumida do bem $x$ pelo agente $i$. Se o preço da unidade do bem escolhido for 1 e considerarmos que cada agente na família se interessa pelo consumo de todos os membros da família, temse que a função utilidade da família é uma média ponderada das utilidades de cada agente 1 e 2 , isto é $u_{1}$ e $u_{2}$, sendo que o peso $\alpha$ que multiplica a utilidade do pai ou da mãe depende da renda dele ou dela e da renda da criança, denotadas, respectivamente, por $y_{1}$ e $y_{2}$. Em outras palavras, quem recebe mais ou menos peso na função utilidade da família é quem traz mais ou menos renda para a família. Assim, o problema de decisão da família é o de maximizar a função utilidade dada por,

$$
\begin{aligned}
& \alpha\left(y_{1}, y_{2}\right) u_{1}\left(x_{1}, x_{2}\right)+ \\
& +\left[1-\alpha\left(y_{1}, y_{2}\right)\right] u_{2}\left(x_{1}, x_{2}\right)
\end{aligned}
$$

sujeita a

$x_{1}+x_{2} \leq y_{1}+y_{2}$

pressupondo-se que 
$\frac{\partial \alpha}{\partial y_{1}} \geq 0, \frac{\partial \alpha}{\partial y_{2}} \leq 0, \frac{\partial u_{1}}{\partial x_{1}}>0, \frac{\partial u_{1}}{\partial x_{2}} \geq 0, \frac{\partial u_{2}}{\partial x_{1}} \geq 0, \frac{\partial u_{2}}{\partial x_{2}}>0 e 0 \leq \alpha \leq 1$

Moehling (2003) estima um modelo muito semelhante a esse, utilizando dados de uma pesquisa de orçamentos familiares de americanos vivendo na área urbana no período 1917-1919. Ela observa que os gastos com a criança são maiores na família quanto maior é a fração de renda vinda dessa criança.

Recentemente, Basu e Van (1998) construíram um modelo com base em duas pressuposições: o axioma da luxúria e o axioma da substituição. No primeiro, considera-se que a pobreza é o que leva as famílias a colocarem seus filhos para trabalhar. Em outras palavras, o tempo da criança, que não é alocado com o trabalho (escola e lazer), é um bem de luxo, não podendo ser adquirido por pais com baixo nível de renda. Assim sendo, pais com renda muito baixa não conseguem retirar os filhos do trabalho. Somente quando a renda aumenta, os pais retiram as crianças do trabalho. Implícita nessa pressuposição é a visão altruísta dos pais, que colocam seus filhos para trabalhar somente se levados pela necessidade.

Considera-se, com base no axioma da substituição, que o trabalho do adulto e da criança são substitutos, sujei- to a uma correção de adulto-equivalência. Mais especificamente, significa que as crianças podem fazer o trabalho dos adultos e vice-versa. Havia uma crença de que as crianças tinham habilidades insubstituíveis, por exemplo, os chamados "nimble fingers", que significa que somente crianças com seus pequenos dedos eram capazes de amarrar os nós adequadamente dos tapetes, ou que somente meninos pequenos eram capazes de entrar e rastejar em pequenos túneis das minas. Entretanto, um estudo sobre tecnologia de produção envolvendo crianças da Índia, realizado por Levison et al. (1998), mostrou que os adultos são tão bons quanto as crianças na confecção manual de tapetes, dando suporte assim ao axioma da substituição.

Para explicar o modelo de Basu e Van (1998), Basu e Tzannatos (2003b) consideram, por simplicidade, que a economia consiste de $N$ famílias e que cada família tem um adulto e $m$ crianças. A produção ocorre utilizando-se somente trabalho. Cada adulto oferta uma unidade de trabalho, enquanto que a criança oferta $y(0<y<1)$ ao realizar um dia de trabalho em tempo integral, o que formaliza o axioma da substituição. Consi- 
deram ainda que o salário de um dia de trabalho realizado por um adulto é $w$ e o da criança é $w^{c}$, tal que, $w^{c}=y w$.

A família decide qual deve ser o seu consumo mínimo tolerável, denominado de consumo de subsistência $s$. Somente se os adultos trabalham tempo integral e a renda familiar cai abaixo do nível de consumo de subsistência é que as crianças são colocadas para trabalhar, refletindo o axioma da luxúria.

$\mathrm{Na}$ Figura 1, o salário dos adultos é representado no eixo vertical. Se esse salário é maior do que $s$, somente adultos ofertam trabalho $(N)$. O segmento $A B$ é parte da oferta de trabalho, pressupondose, por simplicidade, ser perfeitamente inelástica. No momento em que $w$ cai abaixo do nível $s$, os pais fazem as crianças trabalhar para recuperar o nível mínimo de renda aceitável, aumentando a oferta de trabalho. $\mathrm{O}$ segmento $B C$ pode ser uma hipérbole retangular sob a pressuposição de que a família utiliza o trabalho infantil para atingir exatamente o nível $s$. A entrada das crianças no mercado de trabalho continua até que não haja mais trabalho a ser ofertado $(N+m N)$, resultando na forma $A B C F$ da curva de oferta.

\section{Figura 1_Efeito do consumo de subsistência no trabalho infantil}

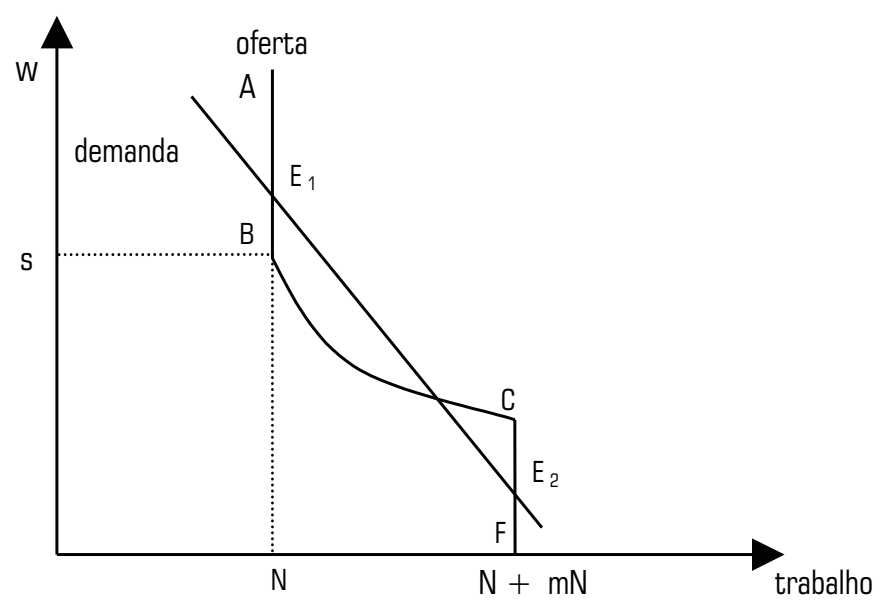

Fonte: Basu e Tzannatos (2003b). 
Considerando uma curva de demanda de trabalho negativamente inclinada, obtém-se o ponto de equilíbrio $E_{1}$, no qual os salários são altos e não existe trabalho infantil e o ponto de equilíbrio $E_{2}$, no qual os salários são baixos e há alta incidência de trabalho infantil.

Observa-se, então, que os autores geram uma situação de equilíbrio múltiplo em que a proibição do trabalho infantil pode mover uma economia de um equilíbrio com baixos salários em que crianças trabalham, para outro equilíbrio com altos salários em que crianças não trabalham. Assim, de acordo com o modelo, a eliminação do trabalho infantil poderia resultar em uma situação em que todos se beneficiariam, com salários aumentando a um ponto tal que famílias pobres poderiam ter um aumento na renda após a eliminação do trabalho infantil.

Entretanto, Basu e Van (1998) enfatizam que a intervenção legal para banir o trabalho infantil não é sempre apropriada. Em economias muito pobres, é possível que a demanda por trabalho seja tão baixa que a única intersecção da curva de demanda com a de oferta ocorra no segmento CF. Nesse caso, eliminar o trabalho infantil pode levar as crianças e seus pais a uma condição de maior pobreza e com risco de inanição.
Ranjan (1999) desenvolve um modelo teórico para uma economia em desenvolvimento, mostrando que o trabalho infantil surge graças à pobreza e às imperfeições no mercado de crédito. O autor mostra que se a família pobre tivesse acesso ao crédito, na presença de altos retornos à educação, ela estaria propensa a colocar o filho na escola em vez de colocá-lo no trabalho. Ademais, mostra que a proibição do trabalho infantil reduz o bem-estar de famílias que tinham a intenção de fazer seus filhos trabalharem. Ele destaca que a proibição, que só pode ser imposta ou cumprida no setor formal da economia, pode piorar a situação das crianças forçando-as a trabalhar no setor informal, sob piores condições de trabalho.

Baland e Robinson (2000), assim como Basu e Van (1998), associam o trabalho infantil a pobreza, mas mostram que é socialmente ineficiente quando utilizado por pais como uma transferência de renda das crianças para eles ou quando há imperfeições no mercado de capitais.

Ranjan (2001) estuda a relação entre desigualdade da distribuição de renda e incidência de trabalho infantil na presença de restrições de crédito. Uma de suas conclusões é que redistribuir renda dos ricos para os pobres pode reduzir a incidência de trabalho infantil. 


\section{4_Análises empíricas}

\section{1_Modelos econométricos}

A maioria dos estudos que tentou estimar os determinantes do trabalho infantil utilizou modelos próbite, próbite bivariado ou lógite multinomial. As estruturas dos modelos são apresentadas a seguir.

Chamarbagwala (2004) na Índia, Kassouf (2002) no Brasil, Jensen e Nielsen (1997) em Zâmbia, entre outros, utilizaram modelos próbite. Nesse caso, a variável dependente assume valor 1 se a criança trabalha e 0 se não trabalha.

A decisão dos pais de colocar a criança na escola e/ou no trabalho resulta de uma decisão de alocação de tempo entre atividades que são interdependentes, competindo entre si com relação ao tempo disponível da criança. Essa interdependência é levada em consideração ao se estimar o modelo próbite bivariado, em que duas equações, uma de trabalho das crianças e outra de freqüência à escola, são estimadas, permitindo a existência de correlação entre os erros. Alguns estudos que utilizaram esse método foram: Kim (2004) para o Camboja e Duryea e Kuenning (2003) e Emerson e Souza (2002b) para o Brasil.

Em muitos países é comum observar crianças que estudam e trabalham concomitantemente, assim como muitas não estão inseridas no mercado de trabalho e também não freqüentam a escola. ${ }^{4}$ Se as diferentes categorias em que a criança está inserida - trabalha e estuda, só trabalha, só estuda, não trabalha nem estuda - são consideradas na análise, o modelo lógite multinomial é o mais comumente utilizado nas análises empíricas (Nkamleu e Gockowski, 2004; Chamarbagwala, 2004; Kassouf, 2002; Grootaert, 1998).

A principal característica do modelo lógite multinomial é a existência de uma única decisão entre duas ou mais alternativas. Lembre-se de que, no modelo próbite bivariado, tanto a decisão de trabalhar como a de estudar ocorria entre duas alternativas. Na verdade, o modelo lógite multinomial é uma generalização do modelo lógite, que não foi descrito anteriormente, mas é muito semelhante ao próbite, só que a função de distribuição considerada é a logística em vez de normal.

Outro modelo alternativo utilizado na literatura, mas com menor freqüência, é o modelo próbite seqüencial. Grootaert e Patrinos (1998) usaram o modelo seqüencial para analisar dados da Costa do Marfim, da Colômbia, da Bolívia e das Filipinas. Os autores pressupõem que inicialmente os pais decidem se a criança estuda ou não e então se vai para o mercado 
de trabalho ou não e então se vai exercer atividades não remuneradas ou não. Esse modelo, apesar de não ter a limitação imposta pela independência das alternativas irrelevantes que ocorre no lógite multinomial, exige pressuposições fortes quanto à seqüência de decisões, que nem sempre representa a realidade.

As estimativas dos parâmetros de todos os modelos apresentados são feitas pelo método de máxima verossimilhança. Como as estimações envolvem funções não-lineares, o efeito marginal de uma variável explanatória sobre a variável dependente não é o coeficiente $\beta$, como no modelo linear, e deve ser calculado para cada caso.

Alguns poucos estudos estimaram a função de oferta de trabalho de crianças, tendo como variável dependente o número de horas de trabalho. Como muitas crianças não trabalham, estimar equações de salário ou horas de trabalho somente para crianças que trabalham, por mínimos quadrados, leva a estimativas inconsistentes devido a seletividade amostral. Ray (2000) e Bhalotra e Heady (2003) estimam equações de horas de trabalho de crianças, utilizando o modelo tóbite, enquanto Bhalotra (2004) utiliza o procedimento de Heckman.

A característica do modelo tóbite é a variável dependente ser censurada. $\mathrm{Na}$ amostra censurada, algumas observações da variável dependente, correspondentes a valores conhecidos das variáveis exógenas, não são observáveis. Nesse caso, os valores dentro de certo intervalo são todos transformados em um único valor. Por exemplo, podemos ter dados de variáveis exógenas de pessoas que não trabalham e de pessoas que trabalham, porém só observamos o número de horas de trabalho de quem trabalha, atribuindo zero aos demais valores.

Nos modelos de seleção amostral, em que o procedimento de Heckman é uma alternativa ao método de máxima verossimilhança, consideram-se duas equações, uma equação de seletividade amostral (participação no mercado de trabalho) e a equação sendo estimada (equação de horas de trabalho). O problema ocorre quando consideramos a equação que descreve o número desejado de horas de trabalho, mas esse número só é observado se o indivíduo trabalha, isto é, se o salário de mercado é maior do que o salário reserva. Segundo Kennedy (2003), utilizar o modelo tóbite para estimar oferta de trabalho não é apropriado, pois nesse modelo a equação de seletividade amostral é a mesma da equação sendo estimada, com um limite fixo determinando quais observações entram na amostra. $\mathrm{Na}$ estimação do número de horas de tra- 
balho, não existe um limite fixo já que a decisão de trabalhar está relacionada ao salário reserva, que é específico para cada indivíduo.

O método de Heckman consiste em estimar a primeira equação (modelo próbite de participação no mercado de trabalho) por máxima verossimilhança e obter as estimativas dos parâmetros. Para cada observação, estima-se a razão inversa de Mill e então se gera a regressão por mínimos quadrados de horas de trabalho em função das variáveis exógenas e da variável razão inversa de Mill para obter estimativas consistentes dos parâmetros.

\subsection{Causas do trabalho infantil}

Nos últimos dez anos, graças à disponibilidade de microdados de pesquisas domiciliares levantadas em diversos países e de análises econométricas voltadas ao tema trabalho infantil, economistas começam a entender melhor o que leva as crianças a trabalhar. A pobreza, a escolaridade dos pais, o tamanho e a estrutura da família, o sexo do chefe, idade em que os pais começaram a trabalhar, local de residência, entre outros são os determinantes mais analisados e dos mais importantes para explicar a alocação do tempo da criança para o trabalho (ver Kassouf, 2001a, para um resumo dos principais estudos empíricos sobre trabalho infantil no Brasil).

Apesar de ser o mais esperado, pobreza é o determinante mais controverso dentro da literatura sobre trabalho infantil. Basu e Tzannatos (2003b) ressaltam que filhos de advogados, médicos, professores e, em geral, da população de classe média alta não trabalham na infância. Vários estudos mostram que o aumento da renda familiar reduz a probabilidade de a criança trabalhar e aumenta a de ela estudar (Nagaraj, 2002; Edmonds, 2001; Kassouf, 2002). Em nível mais macroeconômico, observa-se que as nações que se tornaram mais ricas apresentaram uma redução no trabalho infantil. Tanto na China, como na Tailândia e na Índia, o crescimento do produto interno bruto foi acompanhado pelo declínio do trabalho infantil. Dados em painel, coletados no Vietnam, mostram que, de 1993 a 1998, houve um crescimento per capita do PIB de 6,5\% ao ano, e o trabalho de crianças de 5 a 15 anos, nesse período, caiu $26 \%$. Por outro lado, há estudos empíricos que falharam em encontrar uma relação entre renda e trabalho infantil (Ray, 2000; Barros et al., 1994). Bhalotra e Heady (2003), utilizando dados da área rural de Gana e do Paquistão, mostraram que famílias que são proprietárias de maiores 
áreas de terra onde trabalham tendem a fazer seus filhos trabalharem mais. Como a posse de áreas maiores de terras tipicamente é associada a uma maior riqueza, os autores sugerem que maior nível de pobreza não está relacionado ao aumento do trabalho infantil. A principal razão para esse resultado é que indivíduos com posse maior de terra têm oportunidade de usar de forma mais produtiva a mãode-obra familiar. Portanto, não significa que pobreza não é um determinante do trabalho infantil, mas, sim, que o trabalho infantil responde a incentivos e oportunidades que surgem com as imperfeições no mercado de trabalho.

A maioria das pesquisas realizadas inclui a escolaridade dos pais nas equações de trabalho das crianças, tratando mães e pais separadamente. Entretanto, há um número grande de estudos que inclui somente o nível de escolaridade do chefe da família. Ao interpretar os coeficientes de educação dos pais, é importante saber quais as variáveis incluídas na regressão. Em particular, se a renda da família não for controlada, qualquer efeito da educação dos pais tenderá a incluir o efeito renda, uma vez que pais mais educados tendem a ganhar mais e ser mais ricos. Se for observado que crianças de pais mais educados são menos propen- sos a trabalhar e a renda estiver mantida constante, então uma interpretação plausível para o efeito da educação é em termos de aspiração para o futuro da criança e grau de subjetividade para a preferência na alocação do tempo.

Muitos estudos mostram um efeito negativo da escolaridade dos pais sobre o trabalho das crianças, sendo o tamanho do efeito da escolaridade da mãe superior com relação ao observado para a escolaridade do pai. Entretanto, há uma variação considerável em relação a esse resultado. Bhalotra e Heady (2003) encontram efeito negativo somente para a escolaridade $\mathrm{da}$ mãe sobre o trabalho de crianças da área rural de Gana, assim como Rosati e Tzannatos (2000) no Vietnam e Cigno e Rosati (2002) na Índia. Tunali (1997) não encontra efeito da escolaridade dos pais na Turquia, enquanto Kassouf (2002) obtém efeito negativo e altamente significativo para mãe e pai no Brasil.

A composição familiar é outro importante determinante do trabalho infantil. Apesar de alguns autores - Harman (1970), Da Vanzo (1972) e Rosenzweig (1981) - considerarem-na como variável endógena e parte da decisão familiar envolvendo a troca entre "quantidade e qualidade", muitos estudos incluem o número de irmãos mais novos e mais velhos 
$\ldots \ldots$

5 De Graff et al. citado por

Grootaert e Kanbur (1995). como variáveis exógenas na equação de trabalho das crianças. Muitas crianças trabalham mais quanto maior é o número de irmãos, principalmente mais novos. Estudo realizado nas Filipinas mostrou que a presença do irmão mais velho diminuía a probabilidade de a criança trabalhar. ${ }^{5} \mathrm{Na}$ pesquisa realizada por Kassouf (2002), essa variável ou não apresentou significância estatística ou teve o mesmo comportamento da variável irmãos mais novos, ou seja, de forma geral, o aumento do tamanho da família levou a um aumento da participação das crianças na força de trabalho. Apesar de muitos estudos incluírem indicadores de composição familiar nas equações de trabalho de crianças, poucos consideram os efeitos da ordem de nascimento. Exceção a isso é o estudo de Emerson e Souza (2002a) que, utilizando a PNAD de 1998, estabelecem uma relação sistemática entre a ordem de nascimento e a propensão de a criança trabalhar ou estudar. O último a nascer teve menor probabilidade de trabalhar do que seu irmão mais velho, isto é, algumas crianças trabalham para permitir que outras estudem. Esse fenômeno aparece amplamente em famílias moderadamente pobres, pois nas famílias ricas todas as crianças estarão na escola e fora do trabalho e nas extremamente pobres o inverso ocorrerá.
Praticamente todos os estudos que incluíram como variável exógena o sexo do responsável pela família concluíram que crianças de família chefiada por mulher têm maior probabilidade de trabalhar. Suportam essa hipótese os estudos de Patrinos e Psacharapoulos (1994) para o Paraguai, Grootaert (1998) para a Costa do Marfim e Bhalotra e Heady (2003) para o Paquistão. No Brasil, quase 30\% das famílias têm esse perfil. Barros, Fox e Mendonça (1997), com base na PNAD de 1984, analisaram dados das Regiões Metropolitanas de Recife, São Paulo e Porto Alegre para identificar os efeitos que as famílias nas quais a mãe é chefe exercem sobre o bem-estar das crianças (porcentagem freqüentando escola e não trabalhando), isolando o efeito da pobreza. O fato de haver aumento do trabalho infantil nas famílias chefiadas por mulheres, pode estar mostrando um grau de vulnerabilidade da família que não está sendo captado pela renda, podendo estar relacionado à habilidade de emprestar dinheiro, a de lidar com crises e a de percepção quanto à disponibilidade de diferentes alternativas de trabalho, entre outros fatores.

A área rural abriga uma porcentagem maior de trabalhadores infantis. A inclusão de uma variável binária representando as áreas urbana e rural do país 
tende a ser significativa nas equações de participação da criança no trabalho, mesmo mantendo a renda da família e outros fatores constantes. Esse fato sugere que o nível de pobreza das famílias da zona rural não é o único fator que leva as crianças a trabalhar. Razões adicionais incluem a infra-estrutura escolar mais fraca e menor taxa de inovação tecnológica na área rural que podem desencorajar a freqüência escolar, além da maior facilidade de a criança ser absorvida em atividades informais e a prevalência de trabalhos agrícolas familiares e que exigem menor qualificação.

O efeito da idade da criança sobre a probabilidade de ela trabalhar é sempre positivo ou não significativo. $\mathrm{O}$ término do ensino compulsório e a maior oferta de trabalho disponível às crianças maiores contribuem para o aumento do trabalho numa faixa etária mais avançada.

Outro importante determinante do trabalho infantil, discutido na literatura como associado ao ciclo da pobreza, é a entrada precoce dos pais no mercado de trabalho. Há estudos mostrando que crianças de pais que foram trabalhadores na infância têm maior probabilidade de trabalhar, levando ao fenômeno denominado de "dynastic poverty traps". Wahba (2002), utilizando dados do Egito, mostra que a probabilidade de a criança tra- balhar aumenta em 10\% quando a mãe trabalhou na infância e em 5\% quando o pai trabalhou. Emerson e Souza (2003) chegam a conclusão parecida, analisando dados do Brasil, e atribuem o fenômeno às normas sociais, isto é, pais que trabalharam quando crianças enxergam com mais naturalidade o trabalho infantil e são mais propensos a colocar os filhos para trabalhar.

Finalmente, podemos citar outros determinantes do trabalho infantil, também importantes, mas não tão utilizados na literatura existente, como salário, idade e ocupação dos pais, tamanho da propriedade agrícola onde as crianças trabalham, custos relacionados à escola, medidas de qualidade do estabelecimento de ensino onde a criança está inserida, além de medidas que reflitam a infra-estrutura da comunidade, como disponibilidade de transporte público, rodovias, eletrificação, etc.

\section{3_ Conseqüências do trabalho infantil}

Apesar de haver extensa literatura sobre os determinantes do trabalho infantil, além de muitas iniciativas e recomendações visando combatê-lo, há poucos estudos analisando as conseqüências socioeconômicas do trabalho de crianças e adolescentes. Os principais danos, apontados em discussões sobre o tema, são sobre a educação, o salário e a saúde dos indivíduos. 
Alguns pesquisadores, na realidade, admitem a possibilidade de o trabalho permitir que as crianças estudem, uma vez que serão capazes de cobrir os custos de sua educação, o que seria impossível para uma família de baixa renda (Myers, 1989). Outros defendem que o trabalho exercido pela criança pode elevar seu nível de capital humano, por meio do aprendizado adquirido com esse trabalho (French, 2002). Entretanto, a maioria da literatura parece concordar com a visão de que o trabalho exercido durante a infância impede a aquisição de educação e capital humano. No estudo realizado por Kassouf (1999), Ilahi et al. (2000) e por Emerson e Souza (2003), todos utilizando dados da PNAD para o Brasil, fica claro que, quanto mais jovem o indivíduo começa a trabalhar, menor é o seu salário na fase adulta da vida e essa redução é atribuída, em grande parte, a perda dos anos de escolaridade em razão do trabalho na infância.

Como em muitos países há um número expressivo de crianças e adolescentes que trabalham e estudam, torna-se primordial que se analise não só se o trabalho é responsável pela baixa freqüência das crianças na escola, mas também se o trabalho infantil reduz o desempenho escolar. Bezerra, Kassouf e
Kuenning (2007) utilizaram os dados do Sistema Nacional de Avaliação da Educação Básica (SAEB) de 2003, que possui informações de testes padrões de língua portuguesa e de matemática aplicados aos alunos da $4^{a}$ e $8^{a}$ série do ensino fundamental e da $3^{a}$ série do ensino médio, em escolas públicas e privadas do Brasil e concluiu que o trabalho infantil, principalmente fora do domicílio e durante longas horas, reduz o desempenho escolar em até $20 \%$.

Heady (2003), em estudo realizado em Gana, revelou que o trabalho praticado por crianças tinha um efeito negativo sobre a aprendizagem em áreas chaves, como leitura e matemática. Gunnarsson, Orazem e Sánchez (2004) realizaram uma pesquisa em onze países da América Latina e concluíram que os estudantes que trabalhavam obtinham 7,5\% menos pontos nos testes de matemática e 7\% menos nos testes de idioma do que os alunos que somente estudavam.

Cavalieri (2000) analisou como teria sido o desempenho escolar de crianças de 10 a 14 anos que trabalhavam, caso tivessem sido efetivamente proibidas de trabalhar. Para tal, utilizou uma amostra retirada da PME de 1984 a 1993, selecionando crianças que eram filhos, que na primeira entrevista estudavam, não 
trabalhavam nem procuravam emprego, nem haviam trabalhado anteriormente. Dessa amostra escolheu dois grupos, um composto por crianças que começaram a trabalhar em um dos três meses consecutivos, continuaram trabalhando nos meses em que foram entrevistadas nesse mesmo ano, e permaneceram trabalhando no ano seguinte, i. e., na quinta entrevista (tratamento); e outro constituído por crianças que não trabalharam em nenhum dos períodos (controle). A probabilidade de aprovação foi estimada em função da idade, sexo, escolaridade, região de residência, composição familiar, renda, sexo, condição e atividade do chefe, e educação dos pais. Construiu-se, então, um grupo de controle mediante o procedimento matcbing, uma vez que é impossível observar crianças que trabalham na condição de não-trabalho. Os resultados mostraram que o trabalho possui efeito negativo sobre o desempenho escolar das crianças.

Todos os estudos citados acima tentam minimizar ou eliminar os problemas de endogeneidade que pode ocorrer entre as variáveis de desempenho escolar e trabalho infantil. Os autores mencionam a dificuldade em se determinar o verdadeiro impacto do trabalho precoce sobre a performance escolar, visto que fatores que encorajam o trabalho são parecidos com aqueles que desestimulam a freqüência à escola. Assim, será que é o fato de a criança trabalhar que reduz seu desempenho escolar ou é a baixa qualidade das escolas e a desmotivação do aluno pelo baixo desempenho nos estudos que faz com que ele/ela entre no mercado de trabalho?

A baixa escolaridade e o pior desempenho escolar, causados pelo trabalho infantil, têm o efeito de limitar as oportunidades de emprego a postos que não exigem qualificação e que dão baixa remuneração, mantendo o jovem dentro de um ciclo repetitivo de pobreza já experimentado pelos pais.

Outra conseqüência do trabalho realizado na infância é a de piorar o estado de saúde da pessoa, tanto na fase inicial da vida, quanto na fase adulta. Os efeitos maléficos do trabalho infantil sobre a saúde foram constatados em alguns estudos, apesar de a literatura que abrange esse tópico ser bastante escassa pela falta de dados.

Forastieri (1997) coloca que os locais de trabalho, equipamentos, móveis, utensílios e métodos não são projetados para utilização por crianças, mas, sim, por adultos. Portanto, pode haver problemas ergonômicos, fadiga e maior ris- 
6 Em 2003 o Programa

Bolsa-Escola foi incorporado

ao Programa Bolsa-Família. co de acidentes. $\mathrm{O}$ autor argumenta que as crianças não estão cientes do perigo envolvido em algumas atividades e, em caso de acidentes, geralmente não sabem como reagir. Por causa das diferenças físicas, biológicas e anatômicas das crianças, quando comparadas aos adultos, elas são menos tolerantes a calor, barulho, produtos químicos, radiações, etc., isto é, menos tolerantes a ocupações de risco, que podem trazer problemas de saúde e danos irreversíveis.

Kassouf et al. (2001b), utilizando dados do Brasil, mostram que, quanto mais cedo o indivíduo começa a trabalhar, pior é o seu estado de saúde em uma fase adulta da vida, mesmo controlando a renda, a escolaridade e outros fatores. O’Donnell et al. (2003), ao analisarem o trabalho rural de crianças vietnamitas, concluem que as atividades realizadas durante a infância aumentam o risco de doenças em uma fase posterior da vida.

\section{5_ Implicações de políticas para reduzir o trabalho infantil}

Partindo da pressuposição de que os pais são altruístas, qualquer política que melhore o funcionamento do mercado, de forma a aumentar a renda dos trabalhadores adultos e a diminuir o desemprego, é sempre desejável para reduzir o trabalho infantil. Espera-se que os pais tendo renda suficiente retirarão os filhos do trabalho, colocandoos na escola. Entretanto, existe o risco de o pai, com o aumento da renda, aumentar seu patrimônio, comprando mais terra ou abrindo seu próprio negócio, o que poderia até elevar o trabalho infantil, resultante da criação de um ambiente de produção que emprega crianças com mais facilidade.

Políticas que têm sido largamente analisadas e elogiadas pela eficiência em atingir o objetivo de reduzir o trabalho infantil e aumentar a freqüência escolar são as que premiam as famílias pobres que colocam os filhos na escola e não os colocam no trabalho ou os retiram dele. O programa Bolsa-Escola e Programa de Erradicação do Trabalho Infantil (PETI) no Brasil, ${ }^{6}$ Progresa ou Oportunidad no México, Red de Protección Social na Nicarágua, Food for Education em Bangladesh, Mid-day Meal Schemes na Índia, School Construction e Back to School na Indonésia, são alguns exemplos de programas discutidos e analisados na literatura empírica.

Ravaillon e Wodon (2000) analisam o programa Food for Education na área rural de Bangladesh e concluem que o benefício recebido pelas famílias resultou em elevação significativa da freqüência escolar, mas a redução do trabalho infantil não foi tão expressiva. 
Ferro e Kassouf (2005) avaliaram o impacto dos programas de BolsaEscola sobre o trabalho infantil no Brasil, utilizando os microdados da PNAD 2001, e concluíram que o programa é eficiente na redução do número de horas mensais de trabalho das crianças, mas os resultados não foram conclusivos em relação à decisão da família de inserir suas crianças no mercado de trabalho.

Bourguignon et al. (2002) propõem a utilização de um método de microssimulação para avaliar, ex-ante, os impactos do Bolsa-Escola federal tanto na escolha ocupacional das crianças quanto na pobreza e desigualdade correntes. Os autores estimaram um modelo lógite multinomial para as decisões ocupacionais (estudar e trabalhar, só estudar, só trabalhar, não estudar nem trabalhar), utilizando os dados da PNAD de 1999. Com os parâmetros obtidos, fizeram simulações que possibilitaram prever a escolha ocupacional das crianças sob diferentes hipóteses, relacionadas basicamente ao valor das transferências, e o nível de renda domiciliar crítico para a seleção do candidato. Os resultados mostram que a resposta para a educação é considerável, porém, a proporção de crianças que escolheria trabalhar e estudar não cairia. ${ }^{7}$

Cardoso e Souza (2003) utilizaram os microdados do Censo 2000 para ava- liar, ex-post, o impacto das transferências de renda vinculadas à educação na incidência de trabalho infantil e no engajamento escolar entre os indivíduos de 10 a 15 anos. Concluem que os programas de renda mínima e Bolsa-Escola têm algum impacto na escolaridade e que esse impacto é positivo e significativo, contudo não inibem o trabalho das crianças.

Ao contrário das análises positivas e quase que unânimes com relação às políticas de incentivos à freqüência escolar e à redução ou eliminação do trabalho infantil, as políticas coercivas que punem o empregador ou impõem sanções comerciais ao país que produz mercadorias utilizando trabalho infantil são bastantes polêmicas quanto a sua eficácia. Há estudos mostrando que as sanções comerciais aos produtos de exportação que utilizam trabalho infantil, mais prejudicam a criança do que a ajudam. Primeiramente, porque podem ser usadas como medidas protecionistas pelos países industrializados e também porque podem exacerbar a pobreza nas famílias ao banir o trabalho de crianças que buscam obter renda para sobreviver. Estudo realizado pelo UNICEF (1995) mostra que grande parte das meninas que foram demitidas do trabalho nas indústrias de exportação de tapetes no Nepal acabou se prostituindo. Os autores argumentam que essa proporção deve até apresentar um aumento marginal. 
Sabe-se hoje que não existe uma única política para eliminar o trabalho infantil e a sua persistência por dois séculos é uma evidência clara de que não há uma solução fácil. Entretanto, hoje temos maior e melhor entendimento das causas e conseqüências do trabalho infantil, o que nos permite avaliar e sugerir políticas para reduzi-lo ou erradicá-lo com maior segurança. Não há dúvidas de que o trabalho que envolve risco às crianças deve ser banido, assim como os investimentos na qualidade e disponibilidade de escolas devem ser incentivados, associando-os aos programas de transferência de renda às famílias pobres.

\section{6_Recomendações para futuras pesquisas}

Apesar dos avanços em pesquisas observados, ainda é preciso investir no levantamento e na qualidade dos dados a ser analisados, com ênfase para a obtenção de dados em painel, de dados de crianças de rua, de atividades ilícitas e de informações mais precisas quanto à alocação do tempo das crianças. Ademais, os dados devem ser coletados de forma a permitir um delineamento experimental com grupos controle e tratamento para possibilitar uma avaliação mais correta dos programas sociais.
A maioria das pesquisas trata o trabalho de crianças como homogêneo. No entanto, diferenças de gênero, entre atividades nas áreas rural e urbana, de risco ou não, tempo integral ou parcial, no ramo agrícola, comercial, industrial, etc. devem ser analisadas separadamente, já que suas peculiaridades exigem políticas de combate diferenciadas. Além disso, os diversos fatores envolvidos com a decisão de alocação do tempo da criança para o trabalho precisam ser diferenciados. As abordagens para se tratar de aspectos culturais e de tradição familiar são distintas das de aspectos econômicos, envolvendo pobreza e das de aspectos sociais, envolvendo baixo nível educacional dos pais e falta de visão de longo prazo, por exemplo. Quase a totalidade dos estudos aborda o lado da oferta do trabalho infantil, mas é preciso analisar também o lado da demanda. Entender as razões pelas quais as crianças são contratadas e seus efeitos na estrutura e no lucro das empresas e nos salários e nível de emprego do trabalhador adulto é primordial. 


\section{Referências bibliográficas}

\section{BALAND, Jean-Marie;} ROBINSON, J. A. Is child labor inefficient? The Journal of Political Economy, v. 108, n. 4, p. 663-679, 2000 .

BARROS, R. Paes; FOX; L.; MENDONCA, R. Female-headed households, poverty, and the welfare of children in urban Brazil. Economic Development and Cultural Change, p. 231-257, 1997.

BARROS, R. Paes;

MENDONÇA, R.; VELAZCO,

T. Is poverty the main cause of child work in urban Brazi? Rio de Janeiro: IPEA, 1994.

(Texto para discussão, 351).

BASU, K. Child labor: cause, consequence, and cure, with remarks on international labor standards. Journal of Economic Literature, v. 37, p. 1083-1119, 1999.

BASU, K.; TZANNATOS, Z Child labor and development: an introduction. The World Bank Economic Review, v. 17, n. 2, 2003a.

BASU, K.; TZANNATOS, Z The global child labor problem: what do we know and what can we do? The World Bank Economic Review, v. 17, n. 2, 2003b.
BASU, K.; VAN, P. H. The economics of child labor. The American Economic Review, v. 88, n. 3, p. 412-427, 1998.

BECKER, G.; LEWIS, H. On the interaction between the quantity and quality of children. Journal of Political Economy, v. 81, n. 2, p. S279-S288, 1973

BEZERRA, M.; KASSOUF, A. L.; ARENDS-KUENNING, M. The impact of child labor and school quality on academic achievement in Brazil. In: SEMINÁRIO QUALITY OF EDUCATION IN LATIN AMERICA. Universidad Iberoamericana, Mexico City, fev. 2007.

BHALOTRA, S. Is child work necessary? University of Bristol, UK, 2004. (Working Paper).

BHALOTRA, S.; HEADY, C. Child farm labor: the wealth paradox. The World Bank Economic Review, v. 17, n. 2, 2003.

BOURGUIGNON, F.; FERREIRA, F. H. G.; LEITE, P G. Ex-ante evaluation of conditional cash transfer programs: the case of bolsa escola. Michigan: The William Davidson Institute, 2002. 31p. (Working Paper, 516).
BURRA, N. Born to work: child labor in India. New Dehli: Oxford University Press, 1997.

CARDOSO, E.; SOUZA, A. P. The impact of income transfers on child labor and school attendance in Brazil. São Paulo: USP, 2003. Disponível em: <http://www.econ.fea.usp. br/elianacardoso/ECONBRAS/ cardoso-souza.pdf $>$.

CAVALIERI, C. H. Trabalho infantil e desempenho escolar. In: ENCONTRO BRASILEIRO DE ECONOMETRIA, 22., 2000, Campinas. Anais.. Campinas, dez. 2000.

CHAMARBAGWALA, R. Return to education, child labor and schooling in India. Indiana University, Dept. of Economics, 2004. Mimeo.

CIGNO, A.; ROSATI, F. Child labour education and nutrition in rural India. Pacific Economic Review, v. 7, n. 1, p. $65-83,2002$

DA VANZO, J. The

determinants of family formation in Chile, 1960. The RAND

Corporation R-830, AID.

Santa Monica, CA, 1972
DE GRAFF, D. S.; BILSBORROW, R. E.; HERRIN, A. N. The implications of high fertility for children's time use in the Phillipines. In: LLOYD, Cynthia B. (ed.). Fertility, family size, and structure: consequences for families and children. New York: Population Council, 1993.

DURYEA, S.;

ARENDS-KUENNING, M. School attendance, child labor and local labor market fluctuations in urban Brazil. World Development, v. 31, n.7, 2003.

EDMONDS, E. Will child labor decline with improvements in living standards? Dartmouth College, Department of Economics, Hanover, NH, 2001.

(Working Paper)

EMERSON, P.; SOUZA, A. Birth order, child labor and school attendance in Brazil. University of Colorado, Dep. of Economics, Denver, 2002a. (Working Paper).

EMERSON, P.; SOUZA, A. Barganing over sons and daughters: child labor, school attendance and intra-household gender bias in Brazil. University of Colorado, Dep. of Economics, Denver, 2002b. (Working Paper). 
EMERSON, P.; SOUZA, A. Is there a child labor trap? inter-generational persistence of child labor in Brazil. Economic Development and Cultural Change, v. 51 , n. 2 , p. $375-398,2003$

FERRO, A.; KASSOUF, A. L. Avaliação do impacto dos programas de bolsa escola no trabalho infantil no Brasil. Revista Pesquisa e Planejamento Econômico, PPE, v. 35, n. 3, 2005

FORASTIERI, V. Children at work. Health and safety risks. International Labour Office. Geneva, p. 138, 1997.

FRENCH, J. L. Adolescent workers in the third world export industries: attitudes of young brazilian shoe workers. Industrial and Labor Relations Review, v. 55, n. 2, 2002 .

GROOTAERT, C. Child labor in côte d'ivoire. In: GROOTAERT, C.; PATRINOS, H. (Ed.). The policy analysis of child labor: a comparative study. World Bank, Washington, DC, 1998.

GROOTAERT, C.; KANBUR, R. Child labour: an economic perspective. International Labour Review, v. 134, n. 2 , p. 187-203, 1995.

GROOTAERT, C.; PATRINOS, $\mathrm{H}$. The policy analysis of child labor: a comparative study. World Bank, Washington, DC, p. 245, 1998.
GUNNARSSON, V.; ORAZEM, P. F.; SANCHEZ, M. A. Child labor and school achievement in Latin America. Iowa State University: Department of Economics, 2004. 37 p. (Working Papers Series, 03023).

HARMAN, A. Fertility and economic behavior of families in the Philippines. RM-6385, Rand Corporation, Santa Monica, CA, 1970

HEADY, C. The effect of child labor on learning achievement. World Development, v. 31, n. 2, p. 385-398, 2003. Elsevier Science.

ILAHI, N.; ORAZEM, P.; SEDLACEK, G. The implications of child labor for adult wages, income and poverty: retrospective evidence from Brazil. IMF, 2000. (Working Paper).

\section{ILO (INTERNATIONAL} LABOUR ORGANIZATION). Child labour: targeting the intolerable. Genebra: ILO, 1998. 123p.

ILO (INTERNATIONAL LABOUR ORGANIZATION). Every child counts: new global estimates on child labour. Genebra: ILO, 2002. 51p. JENSEN, P.; NIELSEN, H. Child labour or school attendance? Evidence from Zambia. Journal of Population Economics, v. 10, n. 4, p. 407-424, 1997.

KASSOUF, A. L. Trabalho infantil no Brasil. 1999. Tese (Livre Docência) - USP, Departamento de Economia, Administração e Sociologia da ESALQ, 1999.
KASSOUF, A. L. Trabalho infantil. In: MENEZES, Naércio; LISBOA, Marcos (Ed.).

Microeconomia e sociedade no Brasil. Editora Contra Capa e Fundação Getúlio Vargas, 2001a.

KASSOUF, Ana L. Aspectos sócio-econômicos do trabalho infantil no Brasil. Ministério da Justiça, Secretaria de Estado dos Direitos Humanos. Brasília, 2002. 123p.

KASSOUF, A. L.; MCKEE, M.; MOSSIALOS, E. Early entrance to the job market and its effect on adult health: evidence from Brazil. Health Policy and Planning, Oxford University Press, v. 16, n. 1 , p. 21-28, 2001b.

KENNEDY, P. A guide to econometrics. 5th edition. Blackwell Publishing, 2003.

KIM, D. The determinants of child labor and school attendance in Cambodia. 2004. Mimeo.

LEVISON, D.; ANKER, R. ASHRAF, S.; BARGE, B. Is child labor really necessary in India's carpet industry? In: ANKER, R. et al. (Eds.). Economics of child labor in hazardous industries of India. New Delhi: Hindustan Publishers, 1998.

LEVISON, D.; HOEK, J.; LAM, D.; DURYEA, S. Implications of intermittent employment for child labor estimates. Un. of Minnesota, H. H. Humphrey Institute of Public Affairs. Minneapolis, MN, 2002. (Working Paper).

MARSHALL, A. Principles of economics. 8th edition. Macmillan, 1920.
MARX, K. O Capital. Crítica da Economia Política. Editora Civilização Brasileira, 1968.

MOHELING, C. The incentives to work: working children and household decision-making. Yale University, 2003. (Working Paper).

MYERS, W. Urban working children: a comparison of four surveys from South America. International Labour Review, v. 128, n. 3, p. 321-335, 1989.

NAGARAJ, K. Female and child workers in a household industry.

Madras Institute of Development Studies, Gandihinagar, 2002. (Working Paper).

NKAMLEU, G.; GOCKOWSKI, J. Study os socio-economic factors influencing child labor and schooling in the cocoa sector: a survey in Côte d'Ivoire. 2004. Mimeo.

O'DONNELL, O.; ROSATI, F.; DOORSLAER, E. V. Health effects of child work: evidence from rural Vietnam. 2003. Mimeo.

OIT. Combatendo o trabalho infantil: guia para educadores. Cap. 1. Brasília: IPEC, 2001.

PATRINOS, $\mathrm{H}$; PSACHAROPOULOS, G. Educational performance and child labor in Paraguay. International Journal of Educational Development, v. 15, p. 47-60, 1994.

PIGOU, Arthur. The Economics of Welfare. 4th edition, London: Macmillan, 1932. 
PNAD. Pesquisa Nacional por Amostra de Domicilios. Instituto Brasileiro de Geografia e Estatistica, Rio de Janeiro: IBGE, 2005.

PSACHAROPOULOS, G. Child labor versus educational attainment: some evidence from Latin America. Journal of Population Economics, v. 10, n. 4, p. 377-386, 1997. \{Não se encontra no texto\}

RANJAN, P. An economic analysis of child labor. Economics Letters, p. 99-105, 1999.

RANJAN, P. Credit constraints and the phenomenon of child labor. Journal of Develoment Economics, v. 64, p. 81-102, 2001

RAVAILLON, M.; WODON, Q. Does Chile labour displace schooling? Evidence on behavoiural responses to an enrollment subsidy. The Economic Journal, v. 110, n. 462, p. 158-175, 2000.

RAY, R. Analysis of child labor in Peru and Pakistan: a comparative study. Journal of Develoment Economics, 2000.

ROSATI, F.; TZANNATOS, T. Cbild labor in Vietnam. The World Bank, 2000. Mimeo.

ROSENZWEIG, M. Household and non-household activities of youths: issues of modelling, data and estimation strategies. In: RODGERS, Gerry; STANDING, Guy. (Ed.). Child work, poverty and underdevelopment. ILO, Genebra. 1981.
ROSENZWEIG, M.; EVENSON, R. Fertility, schooling, and the economic contribution of children in rural India: an econometric analysis. Econometrica, v. 45, n. 5, p. 1065-1079, 1977.

TUNALI, I. Young hands at work: child labor in Turkey. Istambul, Loc University, Department of Economics, 1997. Mimeo.

TUTTLE, C. Hard at work in factories and mines: the economics of child labor during the British industrial revolution. Westview Press, 1999.

UNICEF (United Nations Children Fund). Girls in specially dificult circumstance: an action report. Katmandu. 1995.

WAHBA, J. The influence of market wages and parental history on child labor and schooling in Egypt.

University of Southampton,

Dep. of Economics. 2002. (Working Paper).

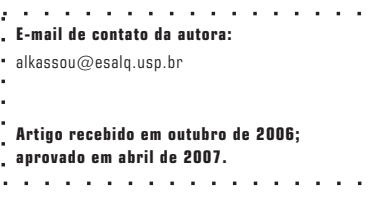

